\title{
A COMPARATIVE STUDY OF STRUCTURAL MODELS OF CORPORATE BOND YIELDS: An Exploratory Investigation ${ }^{\alpha}$
}

\author{
Ronald Anderson ${ }^{y} \quad$ Suresh Sundaresan ${ }^{z}$ \\ J uly 1998, revised J anuary 1999
}

\begin{abstract}
A bstract
This paper empirically compares a variety of ${ }^{-} \mathrm{rm}$-value-based models of contingent claims. We formulate a general model which takes the perpetual coupon bond models of Merton (1974), Leland (1994) and Anderson, Sundaresan and Tychon (1996), as well as some immediate generalizations thereof, as special cases. We estimate these using aggregate time series data for the US corporate bond market, monthly, from August 1970 through December 1996. The data are average yields for industrial corporate bonds rated BBB, Treasury yields, leverage measures derived from the Flow of Funds Accounts, interest coverage measures derived from the National Income Accounts, and volatility measures derived from the stock market. In the basic speci ${ }^{-}$cation with constant default free rates, we ${ }^{-}$nd that models with endogenous bankruptcy barriers (the Leland and the Anderson, Sundaresan and Tychon models) ${ }^{-} t$ quite well. Thus, in these models, variations of leverage and asset volatility are found to account for much of the timeseries variations of observed corporate yields. We then use the estimates to calculate the implied probability of default within $\mathrm{N}$ years. We ${ }^{-}$nd under plausible assumptions on the market riskpremium for levered ${ }^{-} \mathrm{rms}$ that the models produce default probabilties for 5 years or more which are in line with the historical experience reported by Moodys.
\end{abstract}

\footnotetext{
${ }^{x}$ An earlier version of this paper was presented at the Financial Markets Summer Symposium in Gerzensee, Switzerland, J uly 1998, and at the Bank of England/ CEPR conference on Default Risk held in London, September 1998. We appreciate comments from participants of these seminars and particularly E.Altman, S.Hodges, and W.Perraudin. Responsibility for all views expressed and all errors is our own.

YIRES, Universit Catholique de Louvain, and the CEPR. This paper initiated while visiting the Department of Finance, Hong Kong University of Science and Technology. This paper has been partially supported by a Belgian government grant under the Poles d'Attraction Inter-universitaire Program. Email: anderson@ires.ucl.ac.be.

${ }^{\mathrm{z}}$ Graduate School of Business, Columbia University. Email: ms122@columbia.edu
} 


\section{Introduction}

In this paper we estimate structural models of corporate bond yields using monthly observations of yield indices of U.S. investment grade corporate bonds. Following in the tradition established by Merton [32] structural models of corporate bonds treat these as contingent claims on the assets of the ${ }^{-} \mathrm{rm}$. Variations in yield are explained by variations in leverage, asset value volatility, and the riskless interest rate. Interest in structural models of the liabilities of the ${ }^{-} \mathrm{rm}$ is motivated in part by theoretical considerations. These contingent claims models are the extensions of the neoclassical theory of the ${ }^{-} \mathrm{rm}$ to the case of stochastic output in continuous time. As such they link the valuation of 'nancial claims to economic fundamentals and potentially can be imbedded in an equilibrium mode of the production economy. Further motivation for structural models of corporateliabilities is provided by past empirical work which has found that corporate yield spreads over government bonds is related to stock market returns and macroeconomic business cycle indicators (J a [21] and Du [11]).

Despite the appeal of structural models, they have proved di \pm cult to implement successfully and are not very widely used in practice. One problem is that most statistical analyses have employed linear models whereas the theoretical models relate yields to fundamental determinants in a highly non-linear way. Thus these estimates are best viewed as approximations which have veri- ed some of the qualitative predictions of the theory but which cannot be used directly in pricing. Furthermore, structural models have greater data require ments than other approaches. Past serious attempts to implement the Merton mode on U.S. corporate bonds proved disappointing (J ones, Mason, and Rosenfeld [23] [24]). The models did not ${ }^{-} t$ very well and tended to systematically underestimate observed yields when plausible values of asset volatility were employed. In commenting on these results, Fisher Black [5] noted, I This is a costly mode. It uses a lot of computer time. At the end of it all the average error in pricing bonds is $6 \%$. I am surprised that J ones et al are able to create a model with such a large error."

In the face of these results practitioners have tended to adopt pragmatic solutions which attempt to infer fair yields from market yields of other traded instruments that are comparable with respect to rating and maturity. In the simplest application this gives rise to $\backslash$ matrix pricing" wherethe yield of a given issue is derived from a set of yields of traded benchmarks using ad hoc rules for interpolation. Recently a number of advances have been made which give a rigorous statistical basis for inferring issue yields from market benchmarks. Important studies of these so-called \reduced form" models of corporate yields include Litterman and Iben [27], J arrow and Turnbull[22] and Dute and Single ton [12] [13]. This approach draws upon developments in the 1980's in modelling the default-free term structure In particular, these have introduced a variety of ${ }^{\circ}$ exible functional forms giving the conditional probability of default. The results have been encouraging, and these reduced form models are useful in 
some practical applications. However, there are important limitations to this approach.

These studies have proposed a variety of ${ }^{\circ}$ exible functional form which may be calibrated to a given set of benchmarks. Two di ßerent forms calibrated to the same benchmarks may imply signi ${ }^{-}$cantly di ßerent values when pricing some other issue Thus predicted value depends upon the choice of functional form, a dhoice which may not be fully determined on the basis of goodness of ${ }^{-} t$.

A second problem with reduced form models is that for many pricing problems there are no reliable benchmarks. In this case one would like to establish values from ${ }^{-}$rst principles. For example, suppose that a given company has a single 5 year bond outstanding. One might assume that such a bond could be priced using a model calibrated to the generic zero-coupon curve for issues carrying the same rating (see eg., Litterman and Iben for this approach). Suppose the resulting yield prediction is signi ${ }^{-}$cantly below the market yield for this security. Does this represent a trading opportunity or does it indicate that the risks of this security are signi ${ }^{-}$cantly greater than those of the average security within its rating class? It is di \pm cult to know how to answer this question without reference to fundamentals.

A third limitation to corporate bond pricing using a ${ }^{\circ}$ exible reduced form mode calibrated $O{ }^{\circledR}$ of closely related issues is that this approach to pricing individual securities ignores systematic risks in a bond portfolio. It is likely that default events of diverse ${ }^{-} \mathrm{rms}$ are correlated and coincide with cyclical down-turns. This fact is ignored in an approach that treats the bond market as consisting of a large number of isolated segments, each of which contains benchmarks used for calibrating a model which in turn can be used to price the other issues within the segment. Such an approach wastes potentially valuable information deriving from the fact that yields across these segments are partially driven by the same common factors. In contrast, a fundamental models can readily take this into account when it is realized that ${ }^{-} \mathrm{rm}$ asset values may conform to some multi-factor model.

For all of these reasons we feel there is a need for further empirical study of structural models of corporate bonds. An additional reason for undertaking this is that in recent years there has been renewed theoretical work in this area designed to address the limitations encountered with past contingent claims models. The original model of Merton [32] and most other contingent claims analysis assumes that default occurs when the ${ }^{-} r \mathrm{rm}$ 's assets fall to an exogenous absorbing barrier at which point the creditors immediately seize the assets of the ${ }^{-} \mathrm{rm}$, possibly net of some bankruptcy cost. This treatment of ${ }^{-}$nancial distress is inconsistent with observed experience (see, for example, the papers by Franks and Torous [16][17] and Weiss [35]). This shortcoming has given rise to new models which determine the lower reorganization boundary of the mode endogenously. One approach has ben to introduce a game-theoretic mode of the bankruptcy process and in this way address the determinants of deviations from absolute priority (see, Anderson and Sundaresan [2], Anderson 
Sundaresan, and Tychon [3], Anderson, Pan, and Sundaresan [4] and Fan and Sundaresan [14] ). An alternative, but closely related, approach builds on the real options theory of investment decision and treats the liquidation decision as an option (see, Mella-Barral and Perraudin [31]). A third line of modelling follows Black and Cox [6] in assuming that debt service is paid by issuing new equity; the endogenous bankruptcy point is the value of the ${ }^{-} \mathrm{rm}$ such that the market price of equity drops to zero. (See, Leland [28] and Leland and Toft [29]). While there are some similarities across models, their implications for pricing can di Ber signi ${ }^{-}$cantly. To date there has been no attempt to discriminate among these models on empirical grounds.

The purpose of the current study is to see to what extent these new models are able to account for broad time series variations in observed yields of defaultable bonds. Secondarily, it attempts to identify which of the models ${ }^{-}$ts the data best. Speci ${ }^{-}$cally, we formulate a general model which takes the perpetual coupon bond models of Merton (1974), Leland (1994) and Anderson, Sundare san and Tychon (1996), as well as some immediate generalizations thereof, as special cases. ${ }^{1}$ We estimate these using aggregate time series data for the US corporate bond market, monthly, from August 1970 through December 1996.

In the basic speci ${ }^{-}$cation with constant default freerates, we ${ }^{-}$nd that models with endogenous bankruptcy barriers (the Leland and theA Anderson, Sundaresan and Tychon models) 't quite well. Thus, in these models, variations of leverage and asset volatility are found to account for much of the timeseries variations of observed corporate yields. In contrast, the Merton model which assumes an exogenous bankruptcy barrier, does not perform well. When we consider the alternative speci ${ }^{-}$cation which allows for a time-varying default risk-free rate, the performance of the Merton model improves. However, it is still dominated by that of the endogenous bankruptcy models. We then use the estimates to calculate the implied probability of default within $\mathrm{N}$ years. We ${ }^{-}$nd under plausible assumptions on the market risk-premium for levered ${ }^{-} \mathrm{rms}$ that the models produce default probabilities for 5 years or more which are in line with the historical experience reported by Moody's.

The remainder of the paper is organized as follows. In section 2 we describe the data. Section 3 develops the general theoretical model and shows how known models from the literature are nested as special cases. Section 4 presents the empirical estimates. Section 5 is devoted to our conclusions.

\section{D ata}

One of the motivations for structural models of contingent claims is to providea link between corporateliabilities and their fundamental economic determinants.

\footnotetext{
${ }^{1}$ All these models take ${ }^{-} \mathrm{rm}$ value as the underlying stochastic process. In contrast the model of Mella-Barral and Perraudin takes ${ }^{-} \mathrm{rm}$ sales as the driving process. Implementing this would require a di Berent approach from that taken in the current paper.
} 
It is common place to regard equity values for a wide range of ${ }^{-} \mathrm{rm}$ as being determined by a small number of common factors and ${ }^{-} \mathrm{rm}^{- \text {speci }}{ }^{-} \mathrm{c}$ factors. It is much less common to look upon the determinants of corporate bond yields in a similar vein. However, in our view, it is likely that "nancial distress and the recovery rates on claims of distressed ${ }^{-} \mathrm{rms}$ are both highly dependent on systematic factors. However, by the nonlinear nature of debt like claims, the sensitivity to these economic factors will vary signi ${ }^{-}$cantly across di \&erent claims and over time Lower grade claims that are closer to being distressed are likely to be more sensitive to factors a recting equity values; while high grade claims are mostly sensitive to changes in the risk-free term structure The advantage of structural models is that they are speci ${ }^{-}$cally designed to re $^{\circ}$ ect this varying sensitivity under changing circumstances.

One possible application of structural contingent claims modes is to the pricing of speci ${ }^{-} \mathrm{c}$ bond issues of individual ${ }^{-} \mathrm{rms}$. To do so one needs to draw upon information on the asset volatility of the ${ }^{-} \mathrm{rm}$, its capital structure and, in principle, upon the speci ${ }^{-} \mathrm{c}$ covenants of claim we are pricing and of other claims. Working with this mass of information speci ${ }^{-} \mathrm{c}$ to the ${ }^{-} \mathrm{rm}$ requires considerable e®ort and tends to obscure the factors common across ${ }^{-} \mathrm{rms}$. For this reason we have chosen in the present study to implement structural models using aggregate data. Intuitively, indices of corporate bond yields should be more tightly linked to common economic factors, since by averaging the impact of ${ }^{-} \mathrm{rm}$-speci ${ }^{-} \mathrm{c}$ factors will be eliminated. An additional advantage of working with indices of bond yields is that liquidity premia are likely to befairly constant and therefore can be modeled relatively simply. ${ }^{2}$

We use observations of the generic corporate, on-therun bond yields for industrial corporations as reported in the Salomon Brothers Book of Analytical $Y$ ields. This reports monthly observations of yields on 30 year bonds with S\&P ratings of $A A A, A$, and $B B B$ for a relatively long timeperiod, from August 1970 through December 1996. For month $t$ we denote these yields as $y_{t}^{a a a}, y_{t}^{a}$, and $\mathrm{y}_{\mathrm{t}}^{\mathrm{bbb}}$ respectively. It should be noted that by construction these yields are averages of relatively newly issued bonds trading close to par.

During our sample period the U.S. experienced 've recessions, a period of doubledigit in ${ }^{\circ}$ ation, a major stock market crash, and a long period of sustained non-in ${ }^{\circ}$ ationary growth. In the ${ }^{-} r s t$ thre lines of Table 1 we present descriptive statistics for our sample of yields on AAA, A and BBB bonds respectively. It should be noted that both the level of the yield and the volatility of yields vary inversely with credit quality. Note that the autocorrelation coetcients with 1, 2, 3, and 12 month lags are all quite high raising the possibility that the yield series are not stationary. In fact, much of the variation of corporate yields over this period of more than 26 years is likely accounted for by changes

\footnotetext{
${ }^{2}$ It has long been recognized that part of the premium of corporate bond yields over Treasuries $\mathrm{re}^{\circ}$ ects their relatively lower liquidity. (See Fisher [15] and Grinblatt [19]). However, modelling of liquidity e Rects for corporate liabilities is relatively recent and has not yet settled on the determinants of liquidity di Berences across ${ }^{-} \mathrm{rms}$.
} 
in the default-free rate. To verify this we have calculated the spreads of the corporate index over the 30 year U.S. Treasury yield, which we denote as $r_{t}$. Summary statistics are presented in lines 4-6 of Table 1 . In the sample AAA spreads average 71 basis points (b.p.'s). The comparable ${ }^{-}$gures for $A$ and BBB bonds are 124 b.p.'s and 184 b.p.'s. It should be noted that volatility of BBB spreads is roughly twice that of AAA spreads. Indeed, over the sample the BBB varied over a range of almost 300 b.p.'s. The autocorrelation coe \pm cients of the spreads are lower than those of the yields suggesting that there may be a stationary (cointegrating) relationship between corporate and default risk-free yields. Still, these autocorrelation coetcients are relatively high. This might be explicable by the fact that the spreads depend upon other variables which are themselves autocorrelated in the sample. Indeed, it is a basic premise of structural models that the spread should depend upon such factors as leverage and asset volatility as well as the default-free term structure.

Thus, in order to ${ }^{-} t$ structural contingent claims models to monthly time series of yields on generic U.S. corporate bonds, we construct monthly variables to serve as proxies for leverage and asset volatility. Our leverage measures are based on data contained in the annual aggregate balance sheets of non-" nancial corporations contained in the U.S. Federal Reserve's Flow of Funds Accounts. These report various measures of total debt and of net worth. Debt ${ }^{-}$gures are reported as book values. Net worth is reported at market value and is derived as the residual of assets (measured at market value when available) less the book value of liabilities. The accounts also report the total value of equities based on market prices. An inspection of the net worth data reveal very little variation from year to year thus suggesting that in fact they re $^{\circ}$ ect market valuations only very imperfectly. In contrast, measures of the market value of equity vary signi ${ }^{-}$cantly and appear to hold more promise for accounting for observed variations of corporate yields and yield spreads. Therefore, we have concentrated our attention on leverage measures derived from the market value of equity.

We construct a monthly series of the market value of equity from the annual series by ${ }^{-}$rst calculating the monthly average growth rates from two successive year-end ' gures. We do the same thing for theS\&P500 index. Wethen calculate the deviation of the monthly growth rates of the S\&P 500 from the annual average These monthly deviations are combined with the average monthly growth rates of the aggregate market value of equity to obtain a monthly estimate of market value of equity. By this method our estimate tracks monthly ${ }^{\circ}$ uctuations of the S\&P500 but remains consistent with the annual data from the Flow of Funds Accounts. Monthly debt " gures are obtained from annual ' gures by assuming constant geometric growth throughout the year. From these monthly series we obtain monthly estimates of leverage as follows:

LEV $=$ Total Liabilities/ (Total Liabilities+Equity) ${ }^{3}$

\footnotetext{
${ }^{3}$ We also implemented the some of the models using alternative leverage proxies as follows:
} 
Among practitioners it is common to follow a variety of ${ }^{\circ} \mathrm{O}$-based ${ }^{-}$nancial ratios in order to derive information about bond safety. Examples include coverage ratios, pro $^{-}$tability ratios, and cash ${ }^{\circ}$ ow ratios. In this spirit we have investigated some ${ }^{\circ}$ ow-based aggregative measures of debt burden to see whether they add to the explanatory power of structural models of corporate yields. In particular from the U.S. National Income Accounts we used seasonally adjusted measures of aggregate interest payments and corporate pro ${ }^{-}$ts. Monthly estimates of levels were obtained by interpolation. These in turn were used to construct a measure of interest burden as follows:

BURDEN=interest $/$ pro $^{-}$ts

This information must beincorporated within the non-linear functional form of the structural models. A convenient way to do this is to rescale BURDEN so that it has magnitudes of variation comparable to LEV and to combine these two measures linearly to yield a revised leverage measure which we denote as LEV*. ${ }^{4}$ In the estimations we normalize ${ }^{-} r m$ value to be unity so that LEV and LEV* may be interpreted as an aggregate debt to asset ratio. We denote our leverage observation in month $\mathrm{t}$ as $\mathrm{P}_{\mathrm{t}}$.

Our proxy for asset value volatility is derived from the market prices of equity. Given a stock price index, $I_{t}$; we calculate the monthly returns $R_{t}=$

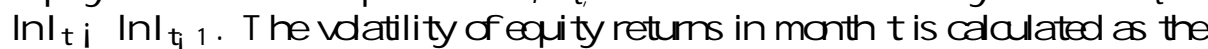
standard deviation of returns over the 12 months ending in month t.. The results reported here are based on the S\&P500 index. We denote this by $\dot{A}_{t}$. For simplicity we take the ratio of asset volatility to equity volatility to be a constant, a, so that the implied proxy for asset volatility is à. The parameter $a$ is determined from the data.

\section{A general structural model of corporate bonds}

Structural models of corporate debt explain variations in the yield on a corporate bond with given contractual features (eg., term, coupon) in terms of variations in ${ }^{-} \mathrm{rm}$ leverage and ${ }^{-} \mathrm{rm}$ asset volatility as well as variations in the default-free term structure. While all structural models share this property, different structural models di ßer in important details and can have very di Berent implications for pricing. In order to compare models and to provide a framework for testing, weintroduce a general framework that gives riseto closed form solutions for the case of perpetual coupon bonds and which nests the models of Anderson, Sundaresan and Tychon (AST) [3], Leland [28], and Merton [32] as special cases.

LEV1=Financial Debt/ (Financial Debt+New Worth); LEV2=Financial Debt/(Financial Debt+Equity); and LEV $3=$ Total Liabilities/ (Total Liabilities+New Worth).

The variables produced systematically worse ${ }^{-}$ts than those we report in the paper and are not reported here.

${ }^{4}$ Speci ${ }^{-}$cally,

$L E V \propto=1: 3 L E V+: 2 \ln (\operatorname{In}(B U R D E N))$ : 
We consider $\mathrm{a}^{-} \mathrm{rm}$ whose assets have a value, $\mathrm{V}$, which follows a stochastic process,

$$
\mathrm{dV}={ }^{1}\left({ }^{-}\right) \mathrm{V} d \mathrm{t}+{ }^{3 / 2} \mathrm{~d} d \mathrm{~d}
$$

where ${ }^{1}$ is the rate of return on ${ }^{-} \mathrm{rm}$ assets, ${ }^{-}$is the cash ${ }^{\circ}$ ow rate, $3 / 4$ is asset volatility, and dz is a Wiener process. Assume zero corporate taxes. Assume a ${ }^{\circ}$ at, non-stochastic default-free term structure with a continuously compounded rate of interest of $r$. We suppose that the ${ }^{-} r m$ has issued a perpetual bond with face value $P$ promising a continuous coupon at rate $c$. Corporate bonds carry the risk that the ${ }^{-} \mathrm{rm}$ will enter into bankruptcy. We assume that the bankruptcy regime in erect allows for the possibility of default which does not induce the liquidation of the ${ }^{-} \mathrm{rm}$. Thus we suppose that the debt service ${ }^{\circ}$ ow actually received by the creditor will be of the state dependent form, $\mathrm{s}(\mathrm{V} ; \mathrm{c}) \mathrm{dt}$. If, however, bankruptcy results in liquidation the creditor will receive the assets of the ${ }^{-} \mathrm{rm}$ net of any liquidation costs. We assume liquidation costs take the general linear form, $K+(1 ; \mu) V$ where $K$ and $\mu$ are constants. Thus at the liquidation barrier the value of the bonds is given by,

$$
\mathrm{B}=\mathrm{M} \operatorname{ax}(\mu \mathrm{V} ; \mathrm{K} ; 0):
$$

Given these speci ${ }^{-}$cations plus additional assumption concerning the drift term, the bonds can be valued using standard techniques. All the models we consider have solutions which take the form,

$$
B=\frac{C P}{r}\left(1 ; P_{d}\right)+P_{d} M \operatorname{ax}\left(\mu V^{\not} i K ; 0\right)
$$

where we can interpret $P_{d}$ as a probability of default and $V^{x}$ as the default barrier. Thus structural models can be viewed as all stating that the value of a risky bond equals the value of a riskless bond times the probability of no default plus the value of the collateral times the probability of default. Structural models of perpetual coupon debt di Rer with respect to how they assess the probability of default and the value of collateral upon default. ${ }^{5}$ We now discuss how special cases of this model correspond to the pepetuity models of Leland, Anderson, Sundaresan and Tychon (AST), and Merton.

In both the Leland and AST frameworks the drift in equation (1) is assumed to be $\left({ }^{1} \mathrm{i}^{-}\right) \mathrm{V}$ so that the value process follows a geometric Brownian motion. In this case, since perpetual bonds do not depend directly upon time, they must satisfy the ordinary di ßerential equation,

$$
\frac{1}{3}^{3 / 4} V^{2} B_{V v}+\left(r_{i}{ }^{-}\right) V B_{v} i r B+s(V ; c)=0
$$

\footnotetext{
${ }^{5}$ Note however that this gives a risk-neutral probability of default. In general it will not be directly comparable to historical default rates.T his issue is discussed below when we interpret our estimates.
} 
where subscripts denote di Berentiation. For general speci ${ }^{-}$cations of state de pendent debt service, $s(\mathrm{~V} ; \mathrm{c})$, and the liquidation boundary there is no known closed form solution to this equation. However, the problem simpli ${ }^{-}$es if for ${ }^{-} \mathrm{rm}$ values in excess of some critical value, $V^{x}$, the bondholder receives contractual debt service at rate $\mathrm{CP}$ and if at the barrier, $\mathrm{V}{ }^{\natural}$, the bondholder receives an amount equivalent to the collateral value in equation 2 . Note that if ${ }^{-} \mathrm{rm}$ value attains the barrier $V^{\sharp}$, we do not necessarily assume that the ${ }^{-} r m$ is liquidated. Indeed in some structural models it is assumed that the ${ }^{-} \mathrm{rm}$ continues operating. For this reason we refer to $V^{\not}$ as the $\backslash$ default barrier". We will discuss below how this barrier is determined in di Berent structural models. Under these assumptions solutions to equation 4 are of the form,

$$
B(V)=A_{1} V^{\circ}{ }^{1}+A_{2} V^{\circ}+U
$$

where ${ }_{1}^{\circ}>1$ and ${ }^{\circ} 2<0: 6 A_{1}, A_{2}$, and $U$ are constants which may be chosen to satisfy boundary conditions. We assume that as the value of the assets of the ${ }^{-} \mathrm{rm}$ grow inde- nitely large, the value of the bond tends toward that of default-risk fre perpetual, i.e.,

$$
B(1)=\frac{C P}{r}:
$$

Thus using the fact that ${ }^{\circ}>1$ we see that $A_{1}=0$ and $U=\frac{c P}{r}$. The second useful boundary condition is that at the default barrier, the value of the bond must match that of the collateral 2 . In this case it can be con ${ }^{-}$rmed that

$$
A_{2}=\frac{M a x\left(\mu V^{a} i K ; 0\right) ; \frac{c P}{r}}{V^{\mathfrak{x}^{\circ} 2}}
$$

This completes the solution for the value of a perpetual bond in this general structural model assuming the default barrier, $V^{\circledR}$ is known. If we de ne

$$
\mathrm{P}_{\mathrm{d}}=\left(\frac{\mathrm{V}}{\mathrm{V}^{\mathrm{x}}}\right)^{\circ} 2
$$

we see that this solution is precisely in the form given in equation (3). Note that ${ }_{2}<0$ so that $0<P_{d}<1$. As $V$ approaches $V$ a from above, this probability of default approaches unity. The Leland and AST models are special case of this framework which di Ber with respect to the assumptions made about ${ }^{-}$nancial distress which will imply a variety of di Berent values of $V^{x}$.

Leland [28] assumes that asset liquidation is costly and that partial liquidations of assets are not possible. Furthermore, he follows Black and Cox [6] in assuming that contractual debt service is made through issues of new equity.

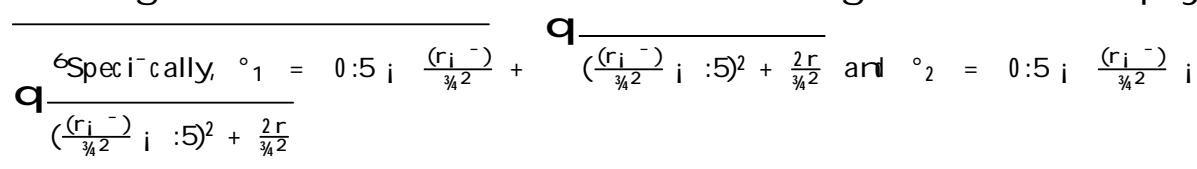


He considers two possible speci ${ }^{-}$cations of the bankruptcy process. In one case he assumes that a net worth covenant leads to the liquidation of the ${ }^{-} \mathrm{rm}$ when the value of the assets of the ${ }^{-} \mathrm{rm}$ falls to the value of the debt when it was originally issued. He views this formulation as approximating the arrangement sometimes used for revolving lines of credit where the borrowing amount and interest rate are ${ }^{-}$xed at inception. In the second, which he views as a more plausible mode of long-term debt, he assumes that debt is protected only by the no-asset-sale covenant. We present this case here He argues that the ${ }^{-} \mathrm{rm}$ will pay contractual service on outstanding debt until the asset value falls to the point where the value of equity is zero. At this point the ${ }^{-} \mathrm{rm}$ is liquidated, and the bondholders receive the available collateral. He makes the further parametric assumptions that ${ }^{-}=0$ and $\mathrm{K}=0$. Under these assumptions he shows that the liquidation (default) barrier is $V_{L}^{a}$ given by the expression,

$$
V_{L}^{a}=\frac{C P}{\left(r+0: 5^{3 / 4}\right)}:
$$

Note that this default barrier (i) is proportional to the contractual debt service, (ii) is independent of the current value of the assets of the ${ }^{-} r m$, (iii) does not depend upon the marginal recovery rate parameter $\mu$, and (iv) is decreasing in level of volatility of assets. Furthermore, note that in this formulation the shareholders do not default on the contract until equity falls to zero at which point the ${ }^{-} \mathrm{rm}$ is liquidated. In other words, in bankruptcy there are no deviations from absolute priority of claims. This feature of the model is unrealistic. A number of studies have documented the fact that " nancial distress often re sults in deviations from absolute priority. In particular, Chapter 11 of the U.S. bankruptcy code seems to allow substantial deviations in favor of common stock (see Franks and Torous [16]). It remains to be seen, however, whether this feature of the model undermines its usefulness in predicting yields on long-term corporate bonds for ${ }^{-} \mathrm{rms}$ far from ${ }^{-}$nancial distress.

It is possible to generalize the Leland framework to allow for a positive cash payout rate, ${ }^{-}$, and for $a^{-} x$ ed liquidation cost, $K$. Under these assumptions the value of the bond is given by equations 3 and 5 above. The liquidation barrier is now,

$$
\mathrm{V}_{\mathrm{GL}}^{\mathrm{a}}=\frac{\mathrm{CP}}{\mathrm{r}} \frac{{ }^{\circ} 2}{\left({ }^{\circ}{ }_{2 \mathrm{i}} 1\right)}:
$$

As in the case of the basic Leland mode, the liquidation barrier is inde pendent of bankruptcy costs. The reason for this is easy to understand. Since Leland assumes that equity holders receive nothing from the bankrupt ${ }^{-} \mathrm{rm}$, he implicitly assumes all bankruptcy costs (both ${ }^{-}$xed and marginal) accrue to bondholders. Therefore, the asset value at which equity becomes worthless will be independent of bankruptcy costs.

Anderson and Sundaresan [2] argue that in order to put the structural modelling of corporate liabilities on solid foundations the starting point should bea 
serious consideration of the bankruptcy regime that applies to the ${ }^{-} \mathrm{rm}$. Working in discrete time they show how a gametheoretic model of ' nancial distress can be imbedded in framework which readily allows valuation of corporate liabilities using standard techniques. Many static bankruptcy models previously seen in the corporate ' nance literature could be adapted to this dynamic setting. They illustrate the technique with a particular model which allows for partial defaults of the debt contract which do not result in the ${ }^{-} \mathrm{rm}$ 's liquidation. Assuming that liquidation may involve a dead-weight loss for creditors, they point out that shareholders may have an incentive to behave strategically in under performing the debt contract even though available cash ${ }^{\circ}$ ows would allow them to pay full service. They show that this feature leads to deviations from absolute priority. Speci ${ }^{-}$cally, by under performing their debt contracts, shareholders are able to increase equity values at the expense of reducing bond values. However, it is not always possible for shareholders to ' $n d$ a reduction in debt that bondholders will agree to, in which case the ${ }^{-} r m$ is liquidation. By assuming that debt service must be met out of available cash ${ }^{\circ}$ ow, they show that some states of the world will result in forced liquidation of the ${ }^{-} \mathrm{rm}$. Thus they show that the cash ${ }^{\circ}$ ow rate, ${ }^{-}$, has a signi ${ }^{-}$cant impact on bond yields and indirectly upon capital structure and optimal security design

Anderson, Sundaresan and Tychon [3] link this game theoretic analysis to more traditional contingent claim modelling by considering the limit of the equilibrium in the discrete time game as the time step tends toward zero. For the special case of perpetual bonds when the debt service may be met either out of cash ${ }^{\circ}$ ows or from new equity issues, they show that the model is a special case of the model above. Their formulation allows only for ${ }^{-} x e d$ bankruptcy cost and thus implicitly assumes that the marginal recovery rate is unity, $\mu=1$. Allowing instead for general $\mu$;it can be shown that the bond values are given by equations 3 and 5 above where the default barrier is $V_{A}^{x} S T$ given by,

$$
V_{A S T}^{x}=\frac{\left(\frac{C P}{r}+K\right)}{\mu\left(1 ; \frac{1}{o_{2}}\right)}
$$

This default barrier is increasing in $\mathrm{c}$ and can be shown to be decreasing in asset volatility, 3/4. However, unlike the default barrier found by Leland, we ${ }^{-}$nd $V_{A S T}^{d}$ is sensitive to the liquidation cost parameters. Speci- cally it is decreasing in the marginal recovery rate, $\mu$ and increasing in the dead-weight liquidation cost, $\mathrm{K}$. The economic interpretation of this is that the greater costliness of liquidation, the greater is the shareholder ability to extract debtservice concessions from creditors. The consequence of this feature is that the bond yields for ${ }^{-} \mathrm{rms}$ for which liquidation is a very remote prospect may still re ect a signi $^{-}$cant premium to compensate for possible partial reductions in debt service Below we refer to the case of $\mu=1$ as the AST model and the case of general $\mu$ as the generalized AST model.

In his analysis of perpetual coupon bonds Merton [32] assumes that contrac- 
tual debt service is met through asset liquidation and continues until such time that all assets are exhausted. This implies that the drift of the asset process is $\left({ }^{1} \mathrm{~V} ; \mathrm{c}\right)$. Furthermore, in terms of the framework above this corresponds to the case ${ }^{-}=0, \mu=0, K=0$. Then he shows that default probability is given by,

$$
P_{d}^{M}=\frac{(2 c P=3 / 4 V)^{(2 r=3 / 4)}}{i\left(2+\frac{2 r}{3 / 4}\right)} M\left(\frac{2 r}{3 / 4} ; 2+\frac{2 r}{3 / 4} ; \frac{i 2 c P}{3 / 4 V}\right)
$$

where $\mathrm{i}(:)$ is the gamma function and $\mathrm{M}(:)$ is the con ${ }^{\circ}$ uent hypergeometric function. Note that this formulation assumes that assets may be liquidated freely and that such partial liquidations do not involve a loss of value These assumptions may be faulted as being counter-factual: bond covenants typically do restrict asset sales, and distressed sales of assets may well involve a loss of value While we view this criticism as important, it remains possible that Merton's formulation might be adequate for modelling bonds of ${ }^{-} \mathrm{rms}$ far from - nancial distress as would seem likely for the case of most investment grade corporate bonds. As a result, we test the Merton restriction below.

It is worth noting that the Merton formulation can be modi ${ }^{-}$ed to restrict asset sales and to allow for costly liquidation. Fan and Sundaresan [14] show that theoptimal payout policy in the Merton model is zero dividends when there is a covenant which precludes asset sales to fund coupons. Using this result, in Appendix 1 we show that the Modi ${ }^{-}$ed Merton (MM) model value of the bond is:

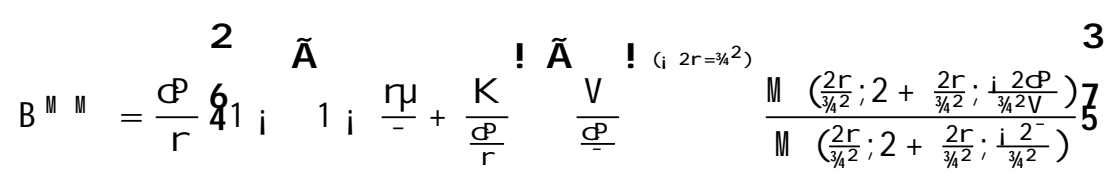

Note that in the modi ${ }^{-}$ed Merton mode, the probability of liquidation de pends on the costs of liquidation.

We now turn to the estimation of the basic Leland, AST, and Merton models using out time-series data set.

\section{R esults}

As discussed in section 2, we are interested to ${ }^{-}$nd a stable relationship between corporate yields and our aggregate measures of leverage and volatility. The structural models of section 3 provide alternative forms of this possible relationship. We implement them empirically using the following estimable form,

$$
\begin{aligned}
& \mathrm{y}_{\mathrm{t}}=,+\mathrm{y}\left(\mathrm{P}_{\mathrm{t}} ; \mathrm{a} \grave{A}_{\mathrm{t}} ; \mathrm{r} ; \mathrm{K} ; \mu^{-}{ }^{-}\right)+\mathrm{u}_{\mathrm{t}} \\
& \mathrm{u}_{\mathrm{t}}=1 / \mathrm{al}_{\mathrm{t}} \mathrm{t}_{1}+{ }_{\mathrm{t}}
\end{aligned}
$$


Here $y_{t}$ is the observed market yield for corporate bonds rated BBB. We have focused on this rating category because of the greater volatility of BBB spreads relative to higher grade issues and because we expect that structure models of contingent claims are likely to be most useful for relatively lower grade issues. The function $y(:)$ is the yield implied by the bond value, $B(:)$ calculated using one of the structural models from Section 2 and is given by the formula, $y=$ $\mathrm{cP}=\mathrm{B}$. The variables $\mathrm{P}_{\mathrm{t}}$ and $a \dot{A}_{t}$ are our proxies for leverage and asset volatility. The ${ }^{-}$xed bankruptcy cost, $\mathrm{K}$; the marginal recovery rate, $\mu$, and the cash ${ }^{\circ}$ ow rate, ${ }^{-}$, are all treated as constants throughout the sample. All the models of section 3 treated the default-free rate as non-stochastic. In this speci ${ }^{-}$cation we treat this as a constant, $r$ :

A number of considerations lead us to include an additive constant, , in the model. First, this may re ect a premium for the illiquidity of corporate bond markets relative to Treasuries. Second, it may re ect a tax erect, since interest on Treasuries is tax deductible for many investors whereas interest on corporates is not. Finally, if the speci cation of $y(:)$ is biased in some respect, the additive constant will correct for this. In the absence of a model of the determinants of liquidity, it would be di \pm cult to decompose a given estimate , of into these separate erects.

We have speci ${ }^{-}$ed the residuals of theyield equation as following a ${ }^{-}$rst-order autoregressive process. This may capture autocorrelation of yield spreads not modeled with our proxies for leverage and asset volatility. Alternatively, it may re ect autocorrelation of liquidity premia.

We estimate the parameters ; $\mathrm{a} ; \mathrm{r} ; \mathrm{K} ; \mu{ }^{-}$; and ${ }^{1 / 2}$ by nonlinear least-squares.

Theresults of the estimates for the full sample are presented in the ${ }^{-}$rst pand of Table 2. The R-square statistic indicate that the two endogenous bankruptcy models ${ }^{-} t$ the data equally well and that the Merton with a ${ }^{-} x e d$ bankruptcy barrier " by the fact that the parameters, ; $a$; and $r$ all estimated with very largestandard errors. The only signi ${ }^{-}$cant erect is found to be the autoregressive parameter, $1 / 2$

In the AST model all the parameter estimates are signi ${ }^{-}$cant. The point estimates of $\mathrm{a} ; \mathrm{r} ; \mathrm{K}$; and ${ }^{-}$are economically plausible; although, the estimated bankruptcy cost of $22 \%$ appears on the high side The estimated value of . is negative suggesting that this parameter is partially correcting for an upward bias of the AST form in this sample. The estimated autoregressive parameter is .83. While this is rather less than the observed autocorrelation of the BBB yield spreads; it suggests that the timeseries variation of yield spreads is not fully accounted for by our proxies for leverage and asset volatility.

The parameter estimates of the Leland model are all signi ${ }^{-}$cant. The coetcient $a$ is estimated to be .91 which suggests that the Leland model must assume approximately twice the asset volatility as does the AST model in order to account for the variations observed in the sample The estimated marginal recovery rate is $-152 \%$ of asset value, which is economically implausible. 
In the ${ }^{-}$rst panel we report summary statistics for the spreads calculated from the models based on the full sample The mean spreads from the estimated models are all close to that observed in the market implying that the models are all unbiased. However, the standard deviations of the estimated spreads, especially for the Merton model, exceed those of the market spread. The ${ }^{-}$tted spreads of the Leland model have a simple correlation with the market of .22; while that of the AST model is .13. The spreads of the Merton model are negatively correlated with the market.

The plots of the market spreads (spbbb) and the ${ }^{-}$tted spread (sbm) are presented in Figures 1-3 for the AST, Leland and Merton models respectively. In Figure 1 we see that at times the AST model is able to track market movements very well. At other times the model and the market drift widely apart. This is particularly apparent in the middle of the sample, corresponding to the end of the 1970's and early 1980's. The same remark applies to the Ledand mode (Figure 2); although, here the over all ${ }^{-} \mathrm{t}$ is somewhat better than in the AST mode. In the case of the Merton model (Figure 3) there are fewer periods when the model tracks the data well.

Overall, these plots suggest the possibility of regime shifts which make it hard to match the models to the market over the entire sample. We investigate this idea by splitting the sample into 3 periods with breaks at October 1979 (coinciding with a major shift in monetary policy in the United States) and in $\mathrm{J}$ une 1984 (following a period of recession and exceptionally high interest rates). The models were reestimated on these subsamples and the results are presented in Table 2, panels 2, 3 and 4. These results do indicate three distinctly di Berent periods. The parameter estimates of the models vary signi ${ }^{-}$cantly across the periods as does their goodness of ${ }^{-} t$.

In the period August 1970 through October 1979, the AST model 'ts the data best. The bankruptcy parameters and the cash ${ }^{\circ}$ ow estimates are lower than for the overall sample. In this model the autoregressive parameter has fallen to .56 suggesting that movements of leverage and volatility are tracking much of the observed variation of BBB yields within this period. The Leland model 'ts the data less well, and the Merton model is still worse

During the period from November 1979 through J une 1984, all the models have a hard time of tracking the observed movements of corporate yields. In all the models, especially the Merton mode, the estimated standards errors are large indicating that the model parameters are not precisely determined by the data.

In the - nal subsample (J uly 1984-December 1996), theendogenous bankruptcy models perform quite well. The R-squares exceed $90 \%$, and the model parameters are estimated quite precisely. Furthermore, the estimated autoregressive parameters equal 0.63 , so that leverage and volatility are accounting for much of the observed variation of BBB yields. The Merton model continues to perform poorly during this subsample.

The performance of the models is also indicated in Table 3 where summary 
statistics of the calculated yield spreads are compared with the observed yield spreads in the market. During the ${ }^{-} r s t$ and last subsamples the Leland and AST models are highly correlated with the market. The spreads ${ }^{-}$tted from the Merton model arefairly highly correlated with the market in the ${ }^{-}$rst subsample but are negatively correlated in the last subsample In the intermediate sample, all the models are negatively related to the market.

Overall these results suggest that the recent eßorts to modify the contingent claims mode to allow for the endogenous determination of the default barrier based on economic fundamentals have led to an improvement of structural models. We saw in section 3 that the assumptions of the AST model and the Leland mode were quite di eerent. In particular, the AST model allows for the possibility of debt renegotiations resulting in deviations from absolute priority whereas the Leland model does not. Despite these di ßerences of starting points we found that the models were fairly close in their abilities to track observed generic yields using aggregate proxies for leverage, asset volatility and the risk-free rate.

In the estimates above we found evidence that the constant default-free rate speci $^{-}$cation of the model was too restrictive When we broke the sample into three separate periods we found the parameter estimates changed substantially and in some cases the ${ }^{-}$ts improved considerably. It must be recognized that the break points of the sample which we chose were somewhat arbitrary. Thus we now investigate a version of the model with a time-varying, default-free rate speci- cation,

$$
\mathrm{y}_{\mathrm{t}}={ }_{,}+\mathrm{y}\left(\mathrm{P}_{\mathrm{t}} ; \mathrm{aA} ; \mathrm{r}_{\mathrm{t}} ; \mathrm{K} ; \mu^{-}{ }^{-}\right)+\mathrm{u}_{\mathrm{t}}
$$

where $r_{t}$ is the 12 month moving average of 30 year Treasury yiedds through month $t$. This model has been estimated for the full sample (7/ 71-12/96), and the results have been reported in Table 4.

Parameter estimates of the models are presented in the ${ }^{-}$rst panel of the table It will be noted that overall goodness of ${ }^{-} \mathrm{t}$ is improved by the introduction of time varying default-free rates. The performance of the Merton mode is particularly improved. Now, its parameters are estimated quite precisely, and the autocorrelation of the residuals has fallen to be in line with that obtained in the endogenous bankruptcy models. In this version the point estimate of bankruptcy costs in the AST model is about $4 \%$ which is quite plausible. With an estimated marginal recovery rate of $95 \%$ the Leland mode implies very similar bankruptcy costs. It is interesting that in comparing the estimates of a across models we see that the Merton mode requires the highest levels of asset volatility to ${ }^{-} t$ the data, the AST requires the lowest asset volatilities, while the Leland model is intermediate between the two. We can also compare estimates of , across models. Here all the estimates are of the samesign and same order of magnitude suggesting that the time-varying default-free rate speci ${ }^{-}$cation may have eliminated a source of bias encountered in the previous speci ${ }^{-}$cation. Assuming the resulting parameter is an estimate of the combined tax and liquidity premia of corporate bonds, we see that the Merton model estimates these to 
be 180 b.p.'s, while they are 160 b.p.'s and 150 b.p.'s in the Leland and AST models respectively.

The second panel of Table 4, presents the summary statistics on the calculated spreads over 30 year Treasury Bonds. It is seen that all the models are unbiased and have comparable volatilities. The correlation with the market is somewhat higher for the AST model than for the Leland model. In this speci ${ }^{-}$cation, the Merton model attains a correlation that is only slightly worse than the endogenous bankruptcy model.

Theresults of the models with time-varying default-free rates are seen graphically in Figures 4-6. When compared to Figures 1-3, it will be noted that the models now are able to roughly track the observed spreads throughout the entire sample Visually, the ${ }^{-}$ts of all three models to the observed spreads are quite similar to one another. A pparently, the time series variations in the level of default free rates enables the models to track the spreads of corporate rates over Treasuries independently of the models' abilities to incorporate information on variations of leverage and volatility. Furthermore, it appears that, once the time-varying default-free rate is taken into account, the relative superiority of endogenous bankruptcy models over the ${ }^{-}$xed bankruptcy barrier model is diminished somewhat.

Finally, we think it is interesting to study the implications of the models for the probability of default and to try to compare these to historically observed default frequencies. Speci ${ }^{-}$cally for each set of parameter estimates and for each month's combination of leverage, volatility, and risk-freerate, we havesimulated by MonteCarlo 1000 paths of the asset process over 20 years. From this we have calculated the frequency that the model hits the mode's default barrier within $1-5,10,15$, and 20 years. It is interesting to compare these predictions with historical experience Recently, Moody's has published the results of an extensive study of default rates from 1920 through 1996 [33] The benchmark produced by the model estimates are not directly comparable to historical " gures since they are calculated on the basis of the risk-neutral probabilities. The calculation of comparable probabilities would require knowledge of the asset drift parameter, 1 : We have approximated this by assuming that this drift re ${ }^{\circ}$ ects a constant risk premium, \pm over the risk-free rate so that the drift in month $\mathrm{t}$ is calculated as, ${ }^{1} \mathrm{t}=\mathrm{r}_{\mathrm{t}}+ \pm$

In - gure 7, the results of the simulations of the AST model estimated assuming time-varying default-free rates are reported for $\pm=5 \%$ and $\pm=0 \%$ (i.e, the risk neutral case). In the same - gure, we plot the historical $\mathrm{N}$-year cumulative default probabilities reported for bonds with Moody's rating of Baa at $\mathrm{N}=0$ [33]. In the case of a zero risk premium the AST model implies default probabilities which greatly exceed the historical observations. However, with positive risk-premia the model implies lower default probabilities. We see that assuming a $5 \%$ risk premium results in default probabilities which are reasonably close to the Moody's ${ }^{-}$gures. However, the ${ }^{-} t$ is certainly not perfect. The AST default probabilities are too high at $1-5$ years and too low at 20 years. 
Stated otherwise, ${ }^{-}$tted probabilities of default conditional on no-default prior to 5 years are too low compared to historical experience.Delianedis and Geske [9] in a recent paper have used the Merton [32] and Geske [18] models to extract risk-neutral default probabilities. Such an approach can lead potentially to better estimates of the probability of rating migrations and defaults.

Finally, as a further comparison with historical observations we may note that, even though they allow for costly bankruptcy, the AST and Leland models are not entirely satisfactory in that they imply that recovery rates on defaulted bonds are quite high relative to actual experience. For example, Altman and Kishore [1] report that the recovery rates on investment grade issues of senior unsecured debt are $48 \%$ of principal. In contrast the ${ }^{-}$tted AST and Leland models imply average recovery rates somewhat over $90 \%$.

\section{Conclusion}

Overall, these empirical results are fairly encouraging for the prospects of ${ }^{-} \mathrm{rm}$ value-based structural models of contingent claims as the basis for studying the pricing of corporate bonds. Most of the movements observed in historical times series of yields on generic corporate bonds can be accounted for in structural models using proxies for leverage and asset volatility derived from the Flow of Funds Accounts and the stodk market. The results suggest that recent modi ${ }^{-}$cations (by A nderson/Sundaresan and Leland )of the contingent claims models to allow for endogenous default barriers have signi ${ }^{-}$cantly improved the performance of the models.

This study is exploratory in nature, and there are clearly many interesting areas for further empirical work with structural models. Our analysis has been simpli ${ }^{-}$ed by theassumption that the bonds are perpetual coupon bonds without call features and that the only underlying state variables is the value of the assets of the ${ }^{-} \mathrm{rm}$. This has allowed us to use closed-form expression for the value of the bonds. Even using fast numerical techniques it would have been very di \pm cult to carry out the huge number of bond valuations involved in the nonlinear regressions (Tables 1-3) without making this assumption. Probably, the assumption of an in nite horizon has been fairly innocuous. As a check we used our parameter estimates of the AST model to numerically calculate the corresponding bond yields for a 10 year bond. Theresulting time series of yields for 317 months was virtually identical to those we have presented in the paper.

Among the avenues which appear relatively more important to be explored are the incorporation of a stochastic risk-freeterm structure in a model with endogenous bankruptcy barrier, more careful modelling of the liquidity premium, and application to speci ${ }^{-} \mathrm{c}$ bond issues using ${ }^{-} \mathrm{rm}$ speci ${ }^{-} \mathrm{c}$ measures of leverage and asset volatility. 


\section{A ppendix 1: Derivation of $\mathrm{G}$ eneralized $\mathrm{M}$ er- ton $\mathrm{M}$ odel}

We prohibit asset sales in the Merton model and introduce a cash ${ }^{\circ}$ ow covenant which says that the ${ }^{-} \mathrm{rm}$ is liquidated when the cash ${ }^{\circ}$ ow generated is insutcient to pay the contractual coupon. This modi ${ }^{-}$cation leads to the implication that the optimal dividend payout policy is to pay no dividends. (See Fan and Sundaresan).

Given this optimal payout condition, we know that the risk-neutral stochastic process followed by the ${ }^{-}$rm's assets is

$$
d V=(r V ; c) d t+V 3 / d B
$$

Then, the fundamental valuation equation is:

$$
\frac{1}{2} 3 / 4 V^{2} D_{V v}+(r V ; c) D_{v} \text { i } r D+c=0 \text { : }
$$

$D^{-}$ne $Z=2 c=3 / 4 V, R=2 r=3 / 4$ and $D(V)=\frac{c}{r}+Z^{R} e^{i} h(Z)$.

Let $G(V)=Z^{R}$ ei $Z h(Z)$.

This reduces to Kummer's equation:

$$
Z h_{z z}+(2+R ; Z) h_{z} ; 2 h=0
$$

which has general solution of the form

$$
C_{1} M(2 ; 2+R ; Z)+C_{2} Z^{i}{ }^{1} R^{R} M(1 ; R ; i R ; Z)
$$

where $C_{1}$ and $C_{2}$ are constants to be determined by the boundary conditions. Therefore, by the property ei $\mathrm{z} M(a ; b ; z)=M(b ; a ; b ; j)$ of thehypergeometric function,

$$
\begin{aligned}
& D(V)=\frac{C}{r}+C_{1}(2 c=3 / 4) V^{i 2 r=3 / 4} M(2 r=3 / 4 V ; 2+2 r=3 / 4 ; ; 2 c=3 / 4 V) \\
& +\mathrm{C}_{2}(3 / 2 \mathrm{~V} V=2 \mathrm{c}) \mathrm{M}(\text {; } 1 ; \text {; } 2 \mathrm{r}=3 / 2 \mathrm{~V} \mathrm{~V} ; \text {; } 2 \mathrm{c}=3 / 2 \mathrm{~V})
\end{aligned}
$$

We use two boundary conditions:

1. When $V$ goes to 1 ,

$D(V)$ goes to $\frac{c}{r}$.

This requires that $C_{2}=0$.

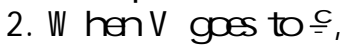

$\mathrm{D}(\mathrm{V})$ goes to $(1 \mathrm{i}$ @ $) \mathrm{V} ; \mathrm{K}$

Using these boundary conditions, we get

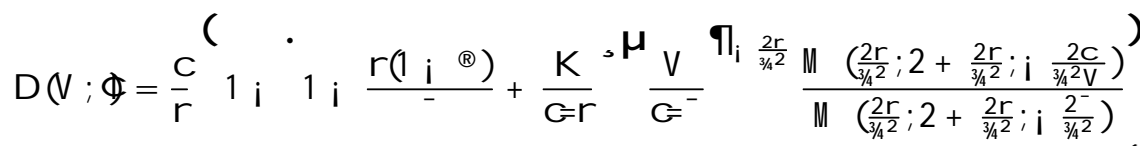


where $i(\phi)$ is the gamma function and $M(\phi \Phi \Phi)$ is the con ${ }^{\circ}$ uent hypergeometric function. Debt value and the total ${ }^{-} \mathrm{rm}$ value are both maximized by choosing minimum payout.

\section{R eferences}

[1] Altman, E.I. and V.M Kishore, 1996, \Almost Everything You Wanted to Know about Recoveries on Defaulted Bonds," Financial Analysts J ournal. November/ December, 57-64.

[2] Anderson, R.W. and Sundaresan, 1996, \Design and Valuation of Debt Contracts," Review of Financial Studies. 9, 37-68

[3] Anderson, R.W., S.Sundaresan, and P.Tychon, 1996, \Strategic Analysis of Contingent Claims,," European Economic Review.40, 871-881.

[4] Anderson, R.W., Y. Pan, and S.Sundaresan, 1997, I Corporate Bond Yield Spreads and the Term Structure," Working paper, Columbia University, Graduate School of Business.

[5] Black, F. , 1985, IComment," in B.M Friedman (ed.) Corporate Capital Structures in the United States. U.Chicago Press, 262-3.

[6] Black, F. and J.C. Cox, 1976, IValuing Corporate Securities: Some E Bects of Bond Indenture Provisions, Lournal of Finance. 31 (May) 351-68.

[7] Chen, N.F. (1991) "Financial Investment Opportunities and the Macroeconomy," J ournal of Finance 46, 529-554.

[8] Cox, J.C. and M. Rubinstein, 1985, Options Markets. Prentice-Hall.

[9] Delianedis G and R. Geske, 1998, \Credit Risk and Risk-Neutral Default Probabilities: Information about Rating Migrations and Defaults" working paper, UCLA.

[10] Dixit, A. and R. Pindyck, 1994, Investment Under Uncertainty. Princeton University Press.

[11] Du ree, G.R., 1998, IThe Relation between Treasury Y ields and Corporate Y ield Spreads," Lournal of Finance.53, 2225-2243.

[12] Du \pm e, D. and K Singleton, 1997, \ A Model of Term Structure of Interest Rate Swap Y ields,"J ournal of Finance. 52,1287-1321.

[13] Du \pm e, D. and K. Singleton, 1996, \Modeling Term Structures of Defaultable Bonds," Working Paper, Graduate School of Business, Stanford University. 
[14] Fan, H. and S. Sundaresan, 1997, IDebt Valuation, Strategic Debt Service and Optimal Dividend Policy," working paper, Graduate School of Business, Columbia University.

[15] Fisher, L. , 1959, \Determinants of Risk Premiums on Corporate Bonds," J ournal of Political Economy. 67, 217-237.

[16] Franks, J . and W. Torous, 1989, \An Empirical Investigation of Firms in Reorganization," J ournal of Finance, 44, 747-779.

[17] Franks, J. and W. Torous, 1994, \A Comparison of Financial Recontracting in Workouts and Chapter 11 Reorganizations," Lournal of Financial Economics. 35, 349-370.

[18] Geske,R., 1977, IT he Valuation of Corporate Liabilities as Compound Options," J ournal of Financial and Quantitative Analysis.12, 541-52.

[19] Grinblatt, M. \An Analytic Solution for Interest Rate Swap Spreads," ..

[20] Ingersoll, J ., 1977, \A Contingent Claims Analysis of Convertible Securities," Journal of Financial Economics. 4, 289-322.

[21] J aree, D., 1975, "Cyclical Variations in the Risk Sturcture of Interest Rates," J ournal of Monetary Economics.1, 309-25.

[22] J arrow, R.A. and S. Turnbull, 1995, "Pricing Derivatives on Financial Securities Subject to Credit Risk," Lournal of Finance 50, 53-85.

[23] J ones, E.P., S.P. Mason and E. Rosenfeld, 1984, IContingent Claims Analysis of Corporate Capital Structures: An Empirical Analysis, J ournal of Finance, 39, 611-625.

[24] J ones, E.P., S.P. Mason and E. Rosenfeld, 1985, \ Contingent Claims Analysis of Corporate Capital Structures: Theory and Empirical Tests," in B.M Friedman (ed.) Corporate Capital Structures in the United States. U.Chicago Press, 239261.

[25] Kim, I. J ., K. Ramaswamy and S.M.Sundaresan, 1993, IValuation of Corporate Fixed-IncomeSecurities," Financial Management, Special Issue on Financial Distress.

[26] Longsta ${ }^{\circledR}$ F.A. and E. S. Schwartz, 1995, \A Simple Approach to Valuing Risky Fixed and Floating Rate Debt," 」 ournal of Finance 50, 789-819.

[27] Litterman,R. and T.Iben, 1991, J ournal of Portfolio Management. (spring) 52-64.

[28] Leland, H., 1994, \Risky Debt, Bond Covenants and Optimal Capital Structure," Journal of Finance 49, 1213-1252. 
[29] Leland, H. and K. Toft, \Optimal Capital Structure, Endogenous Bankruptcy, and the Term Structure of Credit Spreads," Lournal of Finance 51, 987-1019.

[30] Mella-Barral, P., 1995, \Optimal Debt Exchange O Bers," Catholic University of Louvain, IRES DP No. 9522.

[31] Mella-Barral, P. and W. Perraudin, 1997, IStrategic Debt Service," Lournal of Finance.

[32] Merton, Robert C., 1974, \On the Pricing of CorporateDebt: The Risk Structure of Interest Rates," Lournal of Finance, 29, 449-470.

[33] Moody's Investor Services., 1997, \Historical Default Rates of Corporate Bond Issuers, 1920-1996," New York.

[34] Pan, Yonghua, 1994, "T wo Essays in the Design and Valuation of Corporate Se curities and One Essay on International Swaps". Doctoral dissertation, Columbia University.

[35] Weiss, L.,1990, \Bankruptcy Resolution: Direct Costs and Violation of Priority of Claims," J ournal of Financial Economics, 27, 285-314. 
Table 1: Descriptive Statistics, 30-year, Risky Yields and Spreads over Treasuries; 8/70-12/96

\begin{tabular}{|lllllllll|}
\hline & Mean & St. Dev. & Min & Max & AR-1 & AR-2 & AR-3 & AR-12 \\
Yaaa & 0.0938 & 0.0213 & 0.0665 & 0.1650 & 0.9818 & 0.9608 & 0.9404 & 0.7730 \\
Ya & 0.0991 & 0.0232 & 0.0700 & 0.1763 & 0.9826 & 0.9638 & 0.9451 & 0.7829 \\
Ybbb & 0.1051 & 0.0246 & 0.0725 & 0.1850 & 0.9831 & 0.9647 & 0.9455 & 0.7587 \\
Spaaa & 0.0071 & 0.0036 & -0.0005 & 0.0193 & 0.9027 & 0.8629 & 0.8229 & 0.5116 \\
Spa & 0.0124 & 0.0048 & 0.0030 & 0.0259 & 0.9165 & 0.8811 & 0.8444 & 0.4608 \\
Spbbb & 0.0184 & 0.0070 & 0.0081 & 0.0375 & 0.9386 & 0.8988 & 0.8546 & 0.3667 \\
\hline
\end{tabular}


Table 2: Estimation Results

Perpetual Models with Constant Implied Default-free Rate

\begin{tabular}{|c|c|c|c|c|c|c|c|c|}
\hline \multicolumn{9}{|l|}{$\begin{array}{c}\text { Full } \\
\text { Sample }\end{array}$} \\
\hline \multirow[t]{2}{*}{ Merton } & 0.34 & & -0.04 & & & 0.14 & 0.90 & 0.69 \\
\hline & 937803 & & 17980 & & & 17962 & 0.02 & \\
\hline \multirow[t]{2}{*}{ AST } & 0.45 & 0.22 & -0.09 & 0.19 & & 0.17 & 0.83 & 0.82 \\
\hline & 0.09 & 0.04 & 0.03 & 0.04 & & 0.04 & 0.03 & \\
\hline \multirow[t]{2}{*}{ Leland } & 0.91 & & 0.07 & & -1.52 & 0.01 & 0.81 & 0.82 \\
\hline & 0.09 & & 0.003 & & 0.09 & 0.001 & 0.03 & \\
\hline \multicolumn{9}{|l|}{$\begin{array}{c}(8 / 70 \\
-10 / 79)\end{array}$} \\
\hline \multirow[t]{2}{*}{ Merton } & 0.30 & & -0.04 & & & 0.09 & 0.76 & 0.59 \\
\hline & 525368 & & 2320.03 & & & 2317.71 & 0.07 & \\
\hline \multirow[t]{2}{*}{ AST } & 1.11 & 0.08 & -.05 & 0.16 & & 0.12 & 0.56 & 0.85 \\
\hline & 0.61 & 0.38 & 0.08 & 0.15 & & 0.08 & 0.08 & \\
\hline \multirow[t]{2}{*}{ Leland } & 0.91 & & 0.07 & & -1.52 & 0.01 & 0.81 & 0.82 \\
\hline & 0.09 & & 0.003 & & 0.09 & 0.001 & 0.03 & \\
\hline \multicolumn{9}{|l|}{$\begin{array}{l}(11 / 79- \\
6 / 84)\end{array}$} \\
\hline \multirow[t]{2}{*}{ Merton } & 0.30 & & 0.03 & & & 0.12 & 0.78 & 0.59 \\
\hline & 768810 & & 18606 & & & 18588 & 0.08 & \\
\hline \multirow[t]{2}{*}{ AST } & 0.17 & 0.03 & -0.15 & 0.30 & & 0.29 & 0.82 & 0.62 \\
\hline & 0.34 & 0.25 & 1.35 & 1.42 & & 1.35 & 0.08 & \\
\hline \multirow[t]{2}{*}{ Leland } & 0.60 & & 0.06 & & 0.77 & 0.08 & 0.82 & 0.62 \\
\hline & 2.12 & & 0.66 & & 2.06 & 0.66 & 0.08 & \\
\hline \multicolumn{9}{|l|}{$\begin{array}{l}(7 / 84- \\
12 / 96)\end{array}$} \\
\hline \multirow[t]{2}{*}{ Merton } & 0.30 & & 0.00 & & & 0.09 & 0.77 & 0.61 \\
\hline & 549929 & & 2138.07 & & & 2135.93 & 0.06 & \\
\hline \multirow[t]{2}{*}{ AST } & 0.38 & 0.25 & -0.04 & 0.13 & & 0.11 & 0.63 & 0.90 \\
\hline & 0.06 & 0.05 & 0.02 & 0.02 & & 0.02 & 0.07 & \\
\hline \multirow[t]{2}{*}{ Leland } & 0.77 & & 0.07 & & -1.60 & 0.00 & 0.63 & 0.91 \\
\hline & 0.06 & & 0.002 & & 0.06 & 0.0004 & 0.07 & \\
\hline
\end{tabular}

Standard Errors are given below parameter estimates. 
Table 3: Descriptive Statistics, Fitted Spreads, Constant Default-Free Rate Models

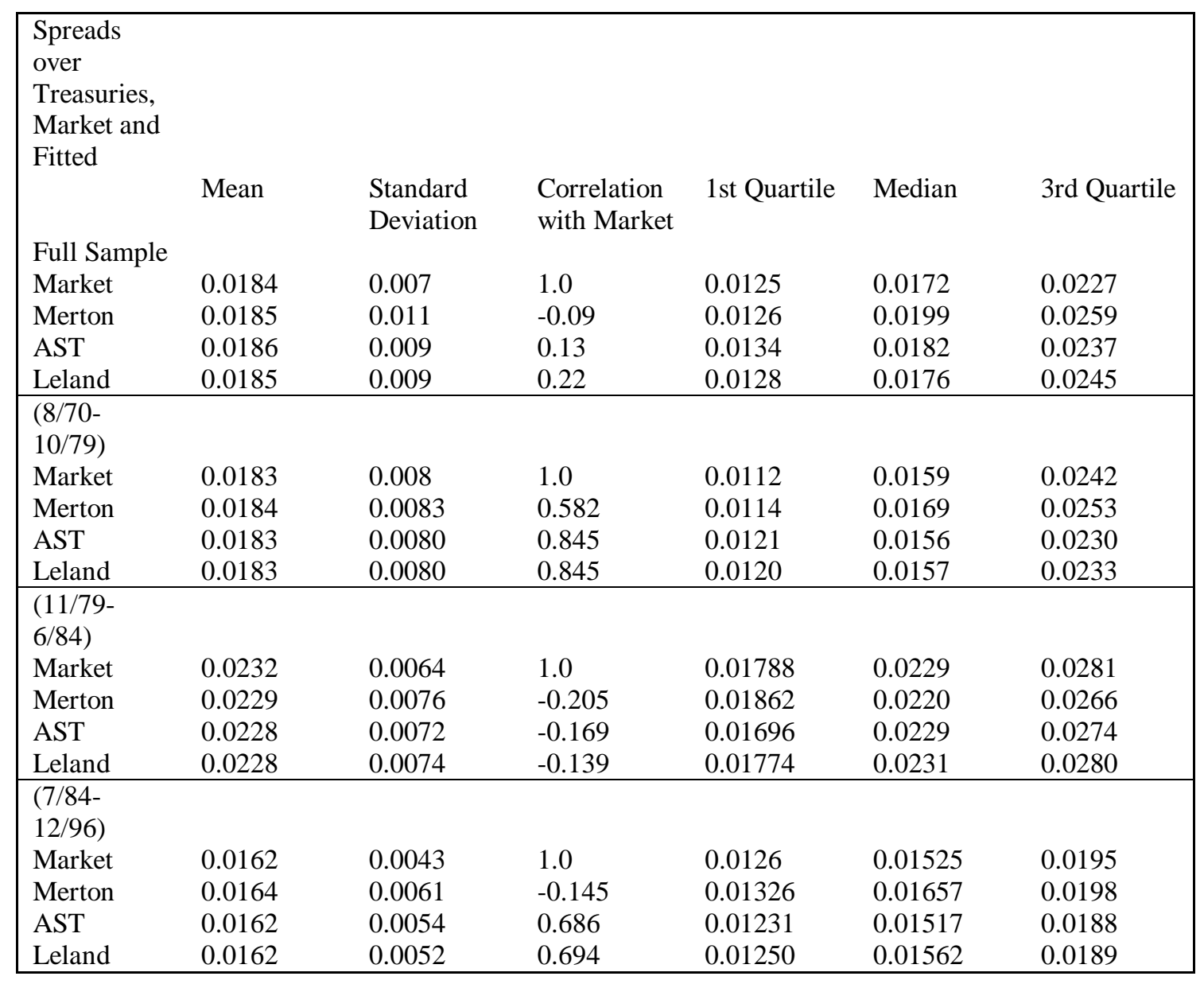


Table 4: Perpetual Models with Time-varying Default-free Rate 7/71-12/96

\begin{tabular}{|c|c|c|c|c|c|c|c|}
\hline \multicolumn{8}{|l|}{$\begin{array}{c}\text { Parameter } \\
\text { Estimates }\end{array}$} \\
\hline & $\mathrm{a}$ & K & $\lambda$ & $\beta$ & $\theta$ & $\rho$ & $\mathrm{R}^{2}$ \\
\hline \multicolumn{8}{|l|}{ Full } \\
\hline \multirow[t]{2}{*}{ Merton } & 0.907 & & 0.018 & & & 0.741 & 0.931 \\
\hline & 0.100 & & 0.001 & & & 0.039 & \\
\hline \multirow[t]{2}{*}{ AST } & 0.545 & 0.041 & 0.015 & 0.068 & & 0.753 & 0.933 \\
\hline & 0.099 & 0.013 & 0.002 & 0.019 & & 0.038 & \\
\hline \multirow{2}{*}{ Leland } & 0.801 & & 0.016 & & 0.948 & 0.756 & 0.933 \\
\hline & 0.104 & & 0.001 & & 0.034 & 0.038 & \\
\hline \multicolumn{8}{|l|}{$\begin{array}{c}\text { Spreads } \\
\text { over }\end{array}$} \\
\hline \multicolumn{8}{|l|}{ Treasuries } \\
\hline & Mean & $\begin{array}{c}\text { Standard } \\
\text { Deviation }\end{array}$ & $\begin{array}{c}\text { Correlation } \\
\text { with } \\
\text { Market }\end{array}$ & $\begin{array}{c}\text { 1st } \\
\text { Quartile }\end{array}$ & Median & 3rd Quartile & \\
\hline Market & 0.018 & 0.007 & 1 & 0.0125 & 0.0169 & 0.0216 & \\
\hline Merton & 0.018 & 0.006 & 0.479 & 0.0139 & 0.0175 & 0.0217 & \\
\hline AST & 0.018 & 0.006 & 0.522 & 0.0136 & 0.0168 & 0.0219 & \\
\hline Leland & 0.018 & 0.006 & 0.517 & 0.0135 & 0.0171 & 0.0218 & \\
\hline
\end{tabular}


Figure 1: AST Perpetual Analysis for 8/70-12/96

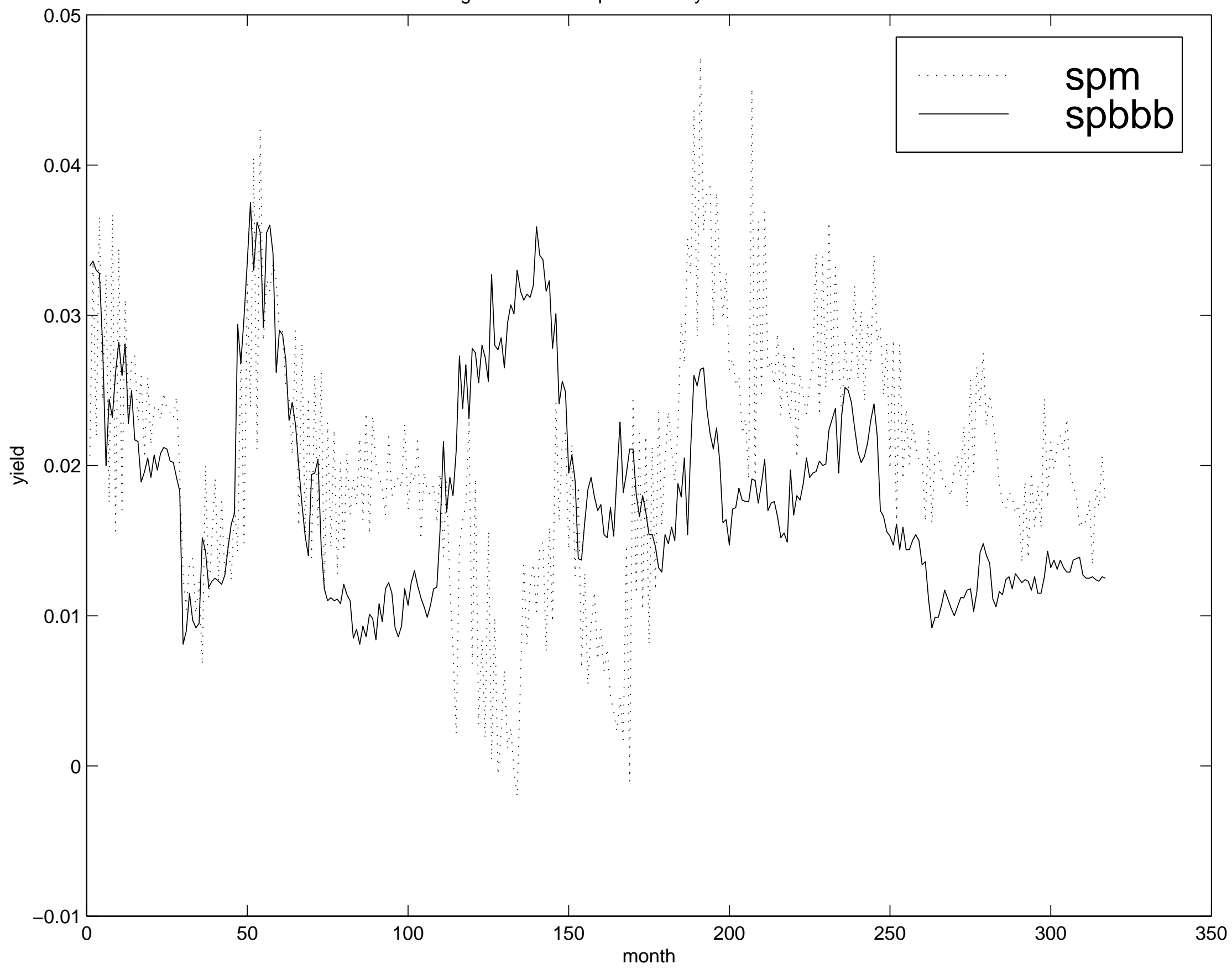


Figure 2: Leland Perpetual Analysis for 8/70-12/96

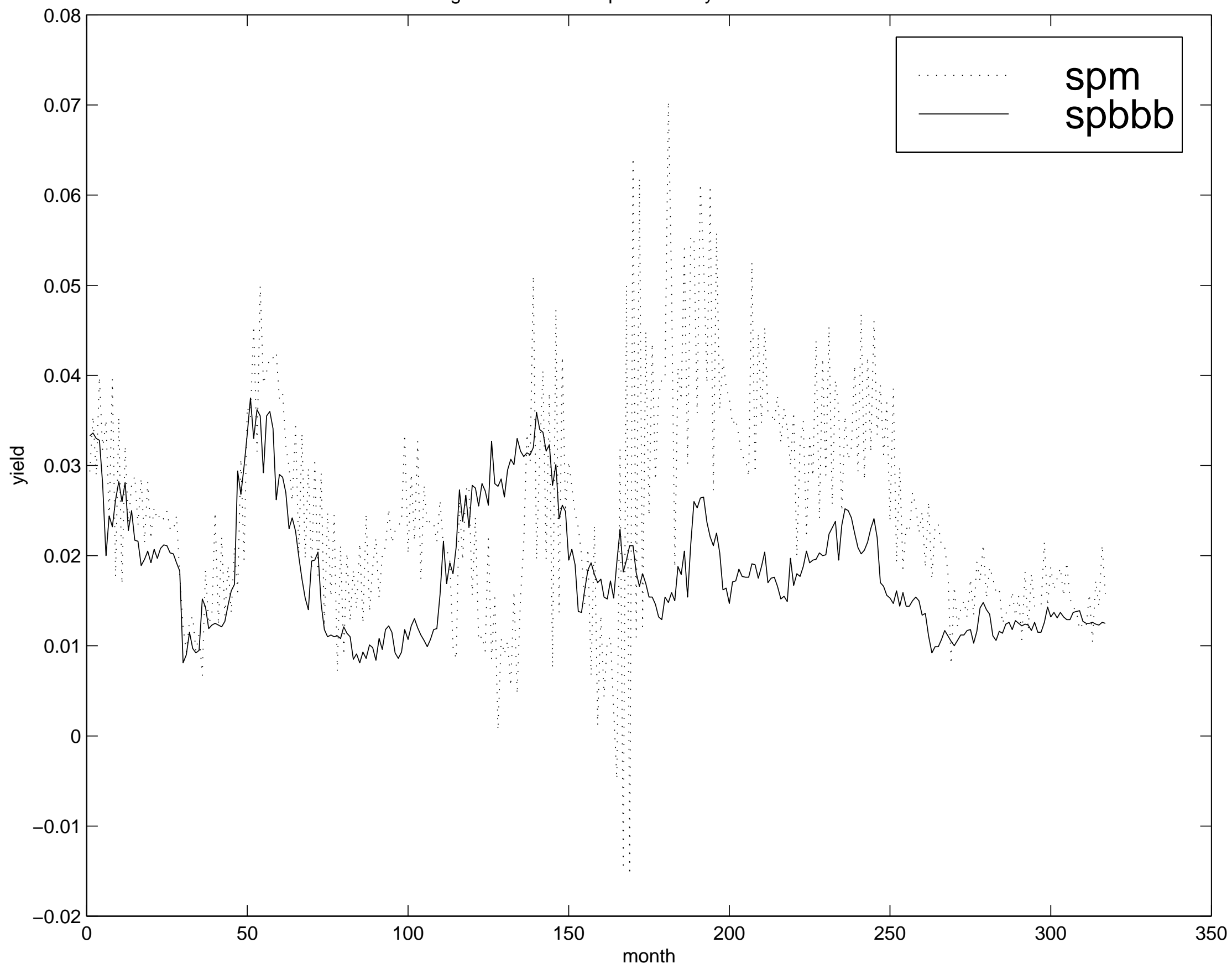


Figure 3: Merton Perpetual Analysis for 8/70-12/96

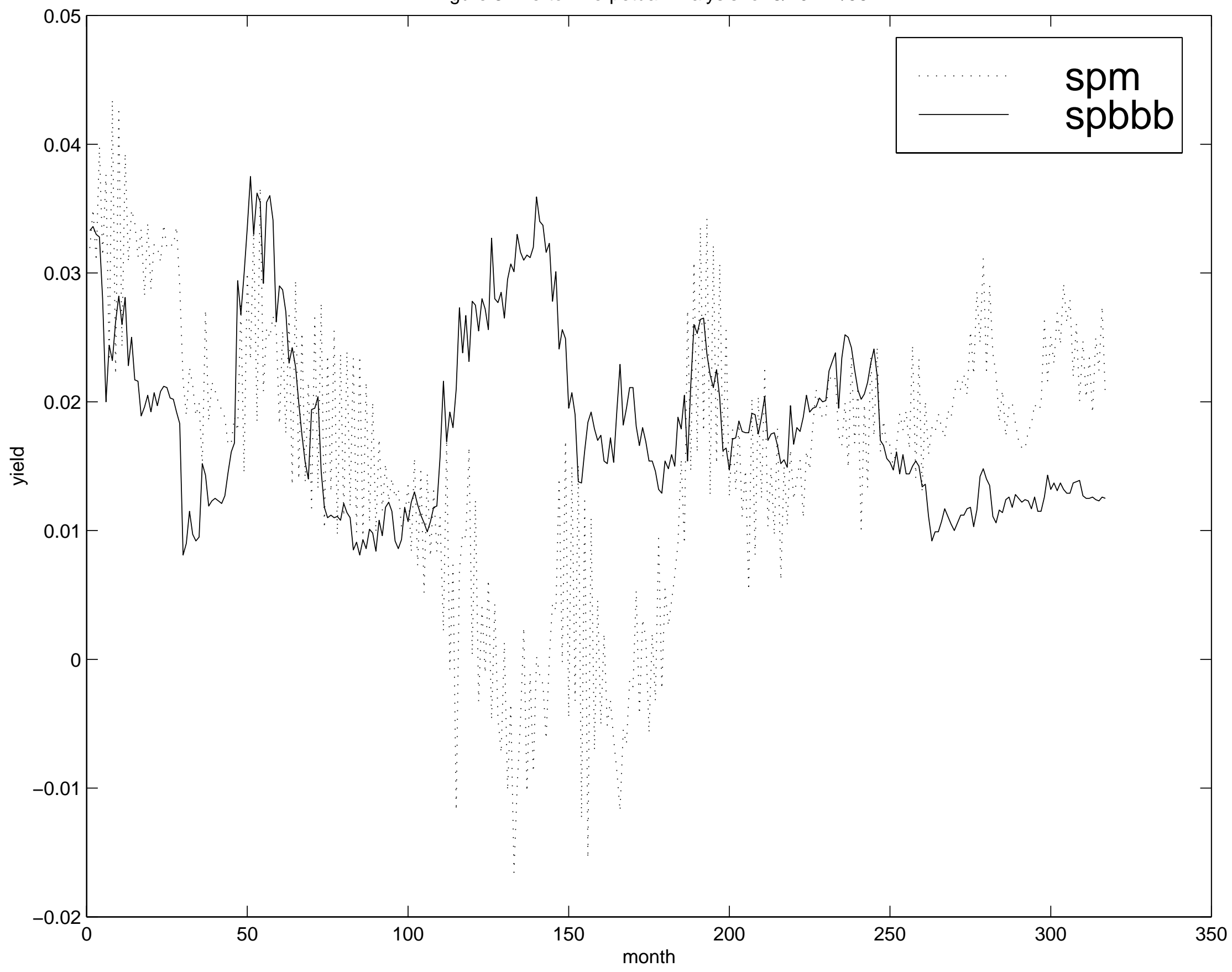


Figure 4: AST Perpetual Analysis for 7/71-12/96

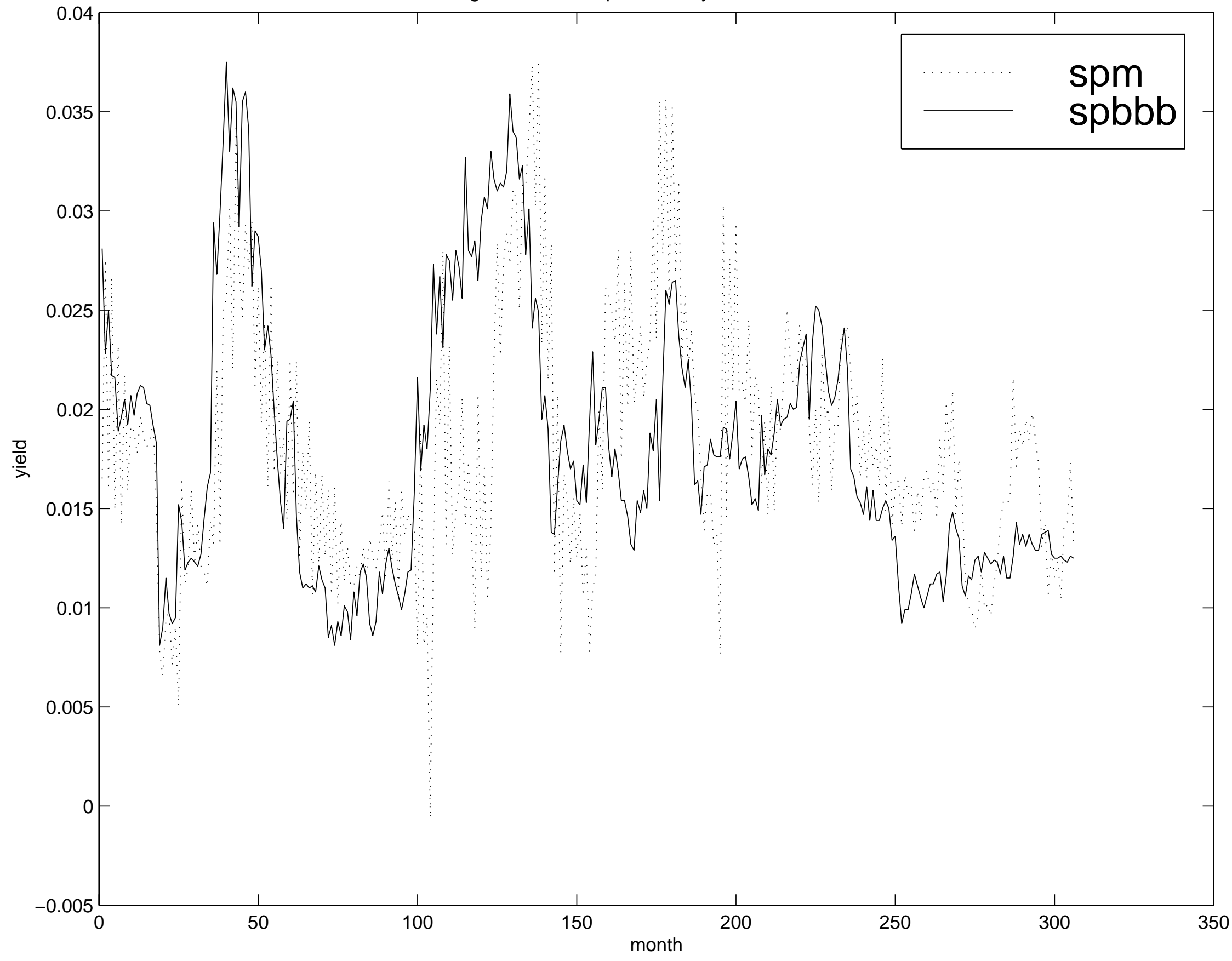


Figure 5: Leland Perpetual Analysis for 7/71-12/96

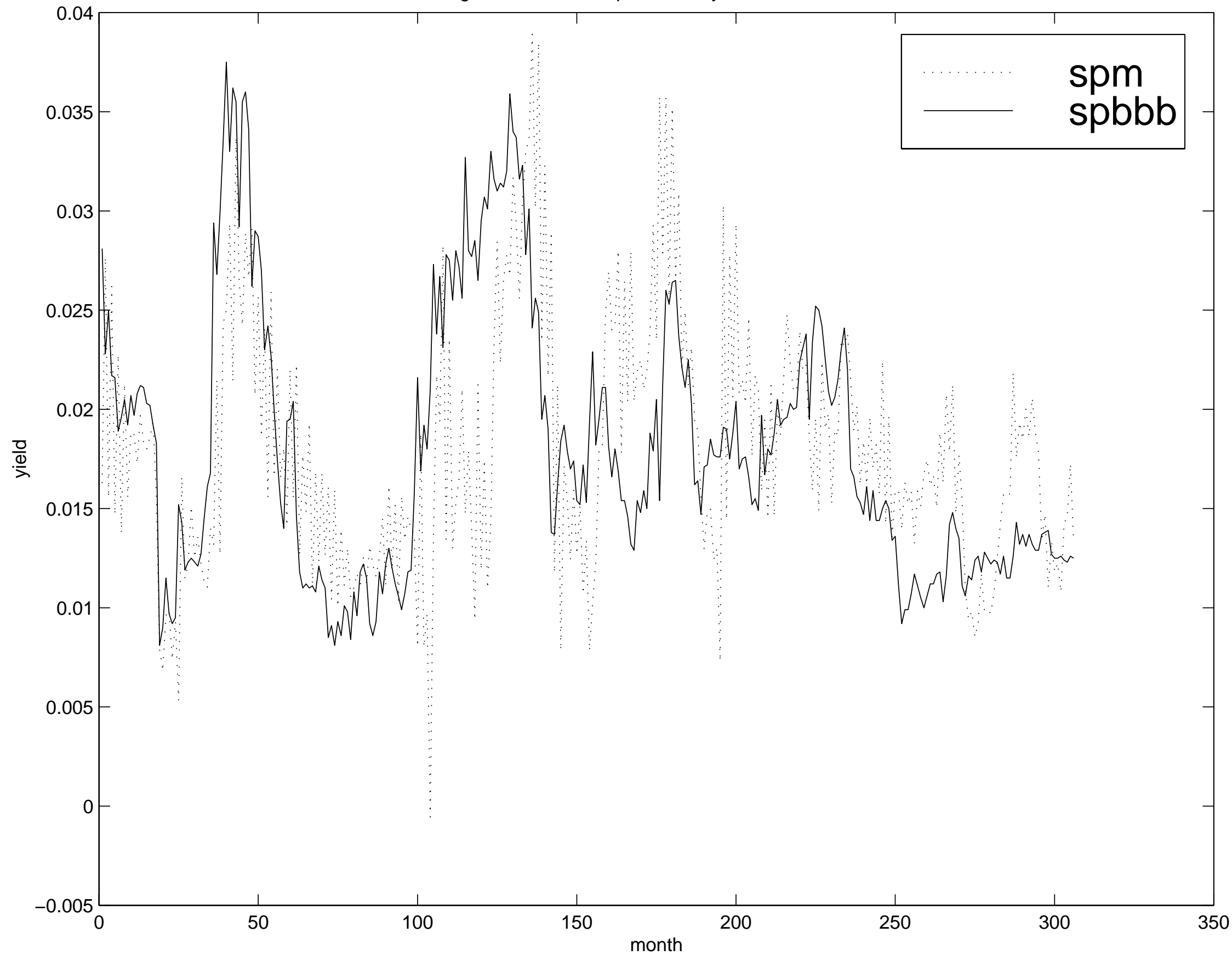


Figure 6: Merton Perpetual Analysis for 7/71-12/96

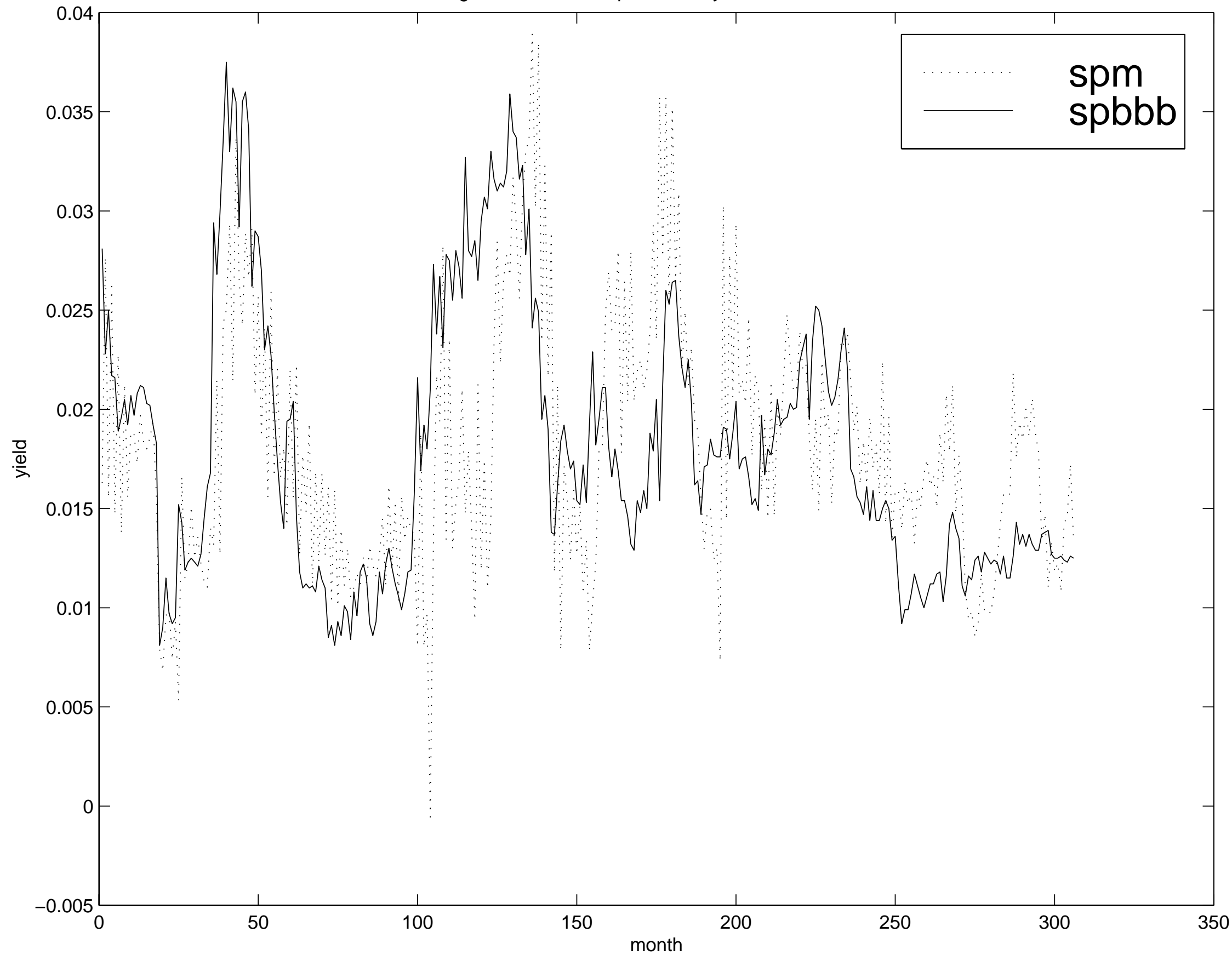




\section{Figure 7: Implied Default Probabilities}

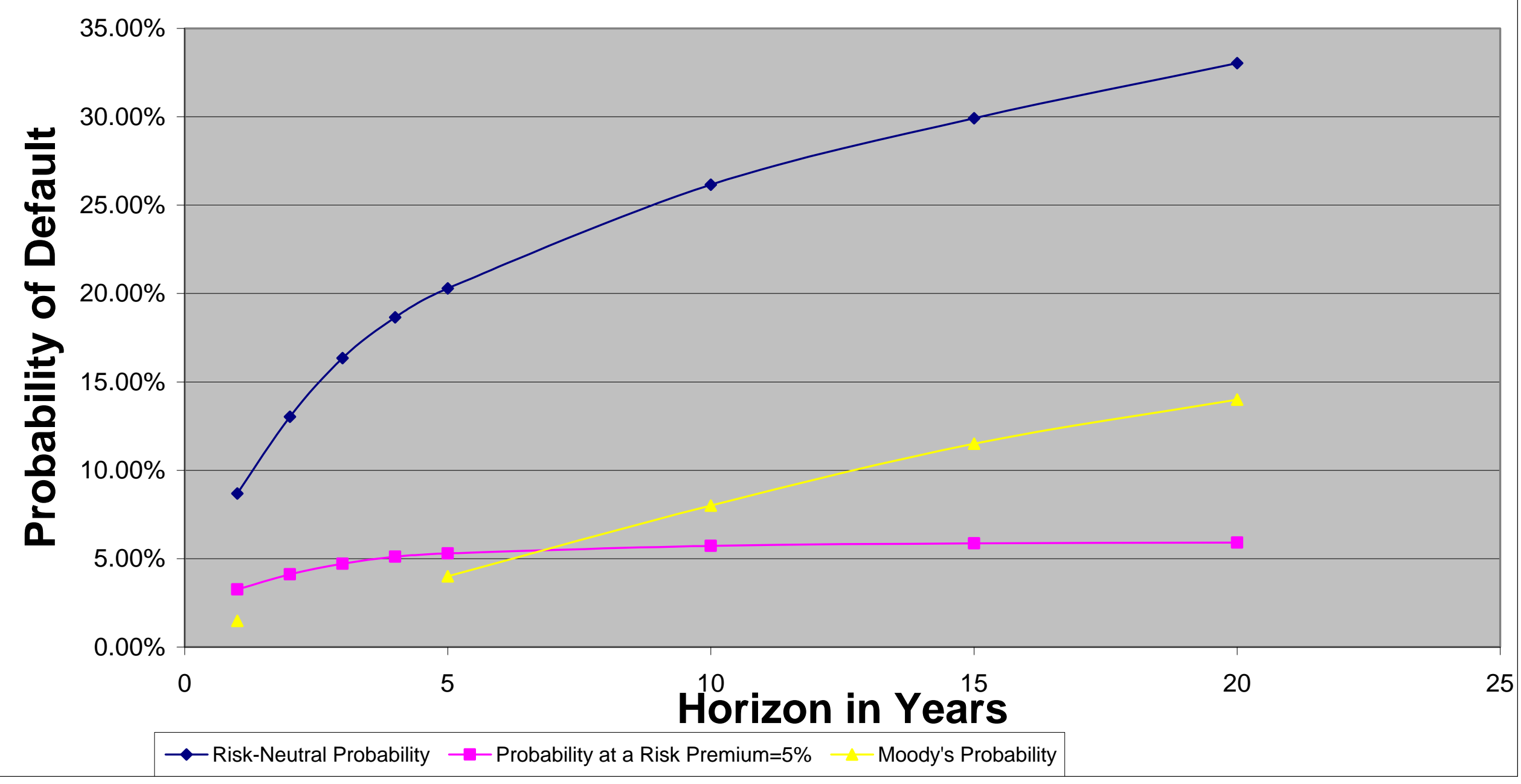

